\title{
ТЕНДЕНЦИИ В СОБСТВЕНОСТТА ВЬРХУ ПАЦИЕНТСКАТА ИНФОРМАЦИЯ
}

\author{
М. Мирчев, А. Керековска
}

TRENDS IN PATIENT INFORMATION OWNERSHIP

\author{
M. Mirchev, A. Kerekovska
}

Рез юме. Живеем в силно дигитализиран и хиперсвързан свят, в който различни видове информация се създават, компилират и трансферират с удивителна скорост и лекота. Технологичните възможности са почти неограничени, но докато осигуряват подобрения за различни аспекти от живота, те също така поставят и важни въпроси, които засягат интересите на индивидите. В областта на общественото здравеопазване това е много чувствителна тема. Покрай динамичното дигитализиране на данни, един от тези въпроси адресира собствеността върху пациентската информация. Това е особено актуален проблем в контекста на нарастващото безпокойство, свързано със защитата на личните данни. Целта е насочена към анализиране на актуални тендениии, засягаши собствеността върху пациентската информация - от нормативен и етичен аспект. Резултатите очертават три основни тенденции - публична собственост върху информацията, частна собственост върху информацията и регулации, небазиращи се на правото на собственост.

$\boldsymbol{S} \boldsymbol{u} \boldsymbol{m} \boldsymbol{m}$ a ry. We live in a highly digitized and hyper-bound world in which information is being created, compiled and transferred extremely easily and fast. Technological capabilities are virtually unlimited and, while providing improvements for different aspects of our lives, they tend to pose important issues, especially when they affect the interests of the people concerned. In the field of public healthcare this is highly sensitive. Along with the rapid digitalization of personal information, one of those important issues refers to the actual ownership of health data, especially with the evermore increasing concern on maintaining data privacy. The aim is to analyze modern trends in patient information ownership from normative and ethical perspective. The results reveal three main trends of patient information ownership - public ownership, private ownership and regulations not based on the right of ownership.

Key words: patient information, ownership, regulation, justice

\section{Въведение}

Много страни са заинтересовани от пациентската информация по различни причини. Не всички от тях са справедливи, етични или оправдани, което извежда проблема за установяване на собствеността върху информацията.

В Европа липсата на дискусия относно кой е собственик на пациентската информация, или кой има най-силната морална претенция да бъде, представлява интересен феномен предвид актуалността на темата, а и предвид факта, че концепцията за „собственост“ фундаментално оформя съвременните общества. Пациентската информация е уникална - и като съдържание, и като вид. Тя е свързана по особен начин с човека, за когото се отнася. Тя е неотчуждаема от него, а това я прави специфичен обект на собственост, който се нуждае от предефиниране и различен дебат - както етически, така и нормотворчески.

Очертават се три основни тенденции при анализирането на проблема за собствеността върху пациентската информация: публична собственост върху информацията; частна собственост върху информацията; регулации, които не се базират на правото на собственост. Основен моралноетичен, но и юридически проблем представлява неяснотата за това, кой е собственик на информацията за пациентите. Докато различни нормативни актове регламентират защитата на лични данни, никой не адресира специфично собствеността върху тях. Не е ясно дали индивидите са собственици или само физически носители. Ако се съгласим, че съществува неизменна и неотменима връзка между даден човек и информацията за него, то справедливото отношение и уважението към автономността предполагат да се внесе яснота.

\section{Це $\Lambda$}

Да се анализират актуални тенденции, засягащи собствеността върху пациентската информация.

\section{Материал и методи}

Използвани са различни литературни източници, които засягат изследвания проблем - научни трудове, философски трактовки и книги, нормативни документи, статии, лекции и презентации от научни, академични и технологични форуми. Приложените методи са исторически, документален и етически анализ.

\section{Резултати и Аискусия}

Работата с електронни здравни досиета и навлизането на информационни технологии в здравеопазването предлага осезаеми предимства по отношение на бързина и ефикасност, но поставя важни въпроси във връзка с достъп, права̀ и употреба на данните. Информационните технологии са имали огромно въздействие, ако разгледаме как се е променил достъпът до информацията за пациента и използването му. [1] Като цяло тази промяна подобрява резултатите от грижите, въпреки че има проблеми, и въпреки факта, че използването или внедряването на технологии варират в различните страни. $[2,3,4]$

Важен аспект, който остава твърде неглижиран, се отнася до собствеността върху информацията. Както отбелязват Jani Koskinen и Kai Kimppa, [5] оскъдността на академичен дискурс в тази сфера е забележителен факт. Академичен дебат по този въпрос в Европа почти напълно отсъства, докато в САЩ, където традиционно въпросите за собствеността са чувствителна тема, съществува по-сериозно разискване. Hall и Schull отбелязват, че само няколко други медико-правни въпроса са по-критични, оспорени или зле разбрани от този, засягащ притежаването на медицинска информация. [6]

Въвеждането на права на собственост върху лични данни се защитава от различни гледни точки. Една от тях, е че овластяването на индивидите би довело до сигурен контрол над техните лични данни или ще спомогне за признаването на присъщата връзка между индивида и данните отнасящи се до него, особено в контекста на пациентската информация. [7, 8] Най-дискутираните подходи към неприкосновеността на информацията като собственост са обикновено взети от гледна точка на икономическия анализ на закона. От особен интерес е част от този икономически аргумент, посочен от автори като Lessig [9], който се позовава на собствеността като регулаторен инструмент и механизъм 
за създаване на обща, по-ефективна система за защита на данните. В теорията на Lessig собствеността е двигателят, който привежда в действие общата система за защита на данните. Lessig изгражда икономически аргумент, според който правилата за собственост биха позволили на всеки индивид да решава каква информация да разкрива и защитава.

Наличието на приложимо особственоствяване на личната информация зависи от законът, признаващ информацията като обект на собственост. Съгласно закона, собствеността обикновено означава юридическо право върху нещо, съчетано с изключителното право това нещо да се притежава. Законодателството дава на собственика разнообразни права, включително права за контрол, използване, печалба, възпрепятстване на другите, които не са собственици да използват обекта на собственост. Тази концепция е ясна, когато обсъждаме физически обекти или недвижими имоти, [10] но се превръща в проблематична, когато я приложим към пациентската информация, и особено ако разглеждаме пациентската информация като обект на интелектуална собственост или на авторско право. [11] Съществуващите закони за собствеността създадени за да отговарят за икономическите нужди са неподходящи и не могат да адресират вьпросите, които възникват например около електронните досиета съдържащи специфична информация за пациентите. [6] Като добавим към тази специфика и информационните технологии, чрез които се поддържат бази данни съдържащи пациентска информация, и които са основен фактор в съвременното здравеопазване и медицина, $[12,13]$ се оказва, че възникват правни, етически и икономически (по-конкретно финансови) проблеми, които възпрепятстват правилната и недвусмислена употреба и въвеждане на електронните пациентски досиета. [14]

Щом обектът на собственост е информацията за пациентите, която включва не само описание на медицинските или здравословни проблеми, но и друга лична и уникална информация за дадено лице, то правата на това лице трябва да лежат в основата на всяка адресираща го дискусия. Собствеността на информацията за пациентите е въпрос, който включва осмислянето на понятието ,self-ownership” - индивидуалното себе-притежаване, свързано с неприкосновеност на личността. Още през XVII век английският философ, лекар и политически теоретик на либерализма Джон Лок използва термина ,self-ownership”, като го обвързва с това, че всеки човек притежава собственост, включваща собствената му личност; над нея има право само той и никой друг. [15] Всеки един човек е собственик на своите способности, качества и специфични особености, и това е от ключово значение, тъй като за разлика от някои други видове собственост, в този случай става дума за характеристики, които не могат да бъдат обект на отчуждаване. [16]

Въпреки че в момента сме свидетели на липсващ или силно ограничен дебат относно притежаването на информация за пациентите, Koskinen и Kimpa [5] установяват, че малкото автори сред академичните среди, които все пак допринасят за разискването на този проблем, изглежда се групират около три основни гледни точки. Според пьрвата, тази информация трябва да бъде публична собственост (например Marc Rodwin). [17] Втората гледна точка е, че самите пациенти трябва да бъдат собственици, както предлагат Koskinen, Kainu, Kimppa. [18] Третият възглед е, че собствеността сама по себе си не представлява проблем и въпросът може да бъде уреден чрез други регулации, а не конкретно със закони за собственост (Evans). [19, 20]

\section{Пациентската информация като публична собственост}

Според Rodwin, [17] публичната собственост върху данните за пациентите е необходима, за да се осигури предоставянето на данни, нужни за ключови правителствени дейности, които насърчават общественото здраве, индивидуалната безопасност на пациентите и развитието на медицинската наука.

Публичната собственост на тези данни е необходима и за ефективен публичен и частен надзор над медицинските технологии, застрахователите, доставчиците на здравни услуги и фирмите, които осигуряват фармацевтични продукти, медицински изделия и медицински материали. Използването на данни директно от медицинските записи на пациентите би позволило подобни оценки да се правят с много по-ниски разходи, по-бързо и с непрекъснато актуализирана информация. Това би предоставило информация за популации и променливи, които иначе не са включени в клиничните изпитвания. [21]

Коментирайки възможността данните на пациентите да бъдат публична собственост и това да бъде изведено по нормативен ред, някои автори смятат, че така се създават рискове за неприкосновеността на личния живот на пациентите. Според Rodwin, [17] рисковете за неприкосновеността на личния живот и правото на конфиденциалност не са поголеми, отколкото ако данните са частна собственост принадлежаща на самите пациенти, институции или организации. Скриването на идентификационните данни в медицинската информация е важен елемент от последващата ѝ употреба. Дори и при анонимизирана информация обаче, в медицинското досие на пациент може да се посочват неговият лекар, дори предпочитана аптека, болница, където се е случила хоспитализация, пощенски код или застраховател. Оказва ce, че като се комбинира това с друга информация, която е публична или закупена от частници, често е възможно да се идентифицира кой е пациента. Накратко, това което преди се е приемало за анонимизирано, всъщност обикновено не е. [22, 23] Следователно, трябва да разработят средства за криптиране на данните и за контролиране на тяхното използване, без значение от статута им на собственост и за какво се използват.

Независимо дали собствеността е публична или частна, ние се нуждаем от защитни законодателни мерки, за да гарантираме поверителността. Публичната собственост обаче позволява по-голям публичен надзор, който може да защити поверителността на пациентската информация.

\section{Пациентската информация като частна собственост}

Пациентската информация като частна собственост на самите пациенти изглежда справедливо решение, стига да не бъде възприето като крайност. Звучи интуитивно пациентите да са собственици, тъй като съществува уникална връзка между индивидите и информацията за тях самите. Тази информация е неотчуждаема от тях. Ако пациентите имат гарантиран достьп и постоянен контрол, те биха могли да бъдат по-добре информирани и да получат разбиране за собственото си здраве и лечение, с което се гарантира неприкосновеността. Пациентьт трябва да знае, че няма ,нищз за мен, без мен“. [24] В идеята, че пациентите трябва да са собственици на своята медицинска информация се застъпва разбирането, че информирането за тяхното състояние и предоставянето на право на достъп не е достатъчно, и че собствеността и контролът върху информацията за пациентите трябва да се предостави на самите тях.

Някои юристи са на мнение, че третирането на личните данни като частна собственост няма непременно да увеличи защитата на личната неприкосновеност, [25] особено в случаите, когато индивидите решат сами да се възползват от възможността да ги продават. Когато индивидите прехвърлят имуществения си интерес към данните, те губят контрол върху използването им; купувачът може на свой ред да ги препродаде без ограничения. Оттук идва и мнението, че ако 
законът предоставя права на собственост върху лични данни, той трябва да ограничи, поне отчасти, правото на препродажба. [26] Ако всеки пациент има изключителни права на собственост върху медицинската си информация, компилаторите на бази данни би трябвало да купуват данните от всяко едно физическо лице за да създадат, например, национална база данни. Разходите за заплащане на всяко физическо лице вероятно биха били по-скоро възпиращи. [3, 27]

Проблематично при този модел на регулиране представлява потенциалният конфликт между частен и публичен интерес. Ако приемем, че пациентите трябва да притежават пълновластие над своите медицински данни, те биха могли да ограничат тяхната употреба, с което да възпрепятстват обществените ползи. Собствеността върху данните може да е неотчуждаема, правото да е неотменимо, но не може да бъде абсолютно. Признаването на пациентите като собственици на своята информация трябва да бъде организирано така, че да се гарантира публичния интерес от употребата на тази информация.

\section{Регулиране на пациентската информация без да се засяга правото на собственост}

Този модел на регулиране на данните е единственият, който намира реално приложение днес. Различни нормативни актове, като европейските директиви и регламенти, [28, 29] гарантират защитата на личните данни на индивидите, но без да се посочва дали те са собственици на своите лични (медицински) данни, или само техни физически носители. Предвид огромния пазар за пациентска информация, това игнориране на въпроса за собствеността може би не е толкова учудващо. Ако чрез нормативен акт се посочи конкретен собственик, той би имал икономическа претенция към употребата на информацията, което би могло да е в конфликт с различните интереси на други, включително и с обществения интерес.

\section{Закиючение}

Предвид съдържанието си, пациентската информация е изключително важна за всеки индивид. Тази информация обаче се използва от различни заинтересовани страни, което осветлява нуждата от идентифициране на конкретен собственик на данните. Пациентската информация е уникален вид информация, което прави обяснението ѝ през призмата на традиционните концепции за собственост невъзможно. Тя не се вписва в конвенционалното схващане за интелектуална собственост и не може да бъде обект на авторско право по съществуващите законови норми. Самото понятие „собственост“ в контекста на информацията за пациенти се нуждае от предефиниране. То може да се обясни чрез собствеността, която всеки човек има над самия себе си; това са данни, които са неотчуждаеми от човека, за когото се отнасят.

В рамките на ЕС не съществува нормативен акт, който изрично да регламентира употребата на пациентска информация през концепцията за собственост. Директивите и регламентите, засягащи личната информация, са насочени директно към регулиране на протекцията, като никой нормативен акт не адресира собствеността върху тези данни. Не на последно място, липсата на яснота кой е собственик на пациентската информация е в конфликт с автономността като етически императив, което потенциално се отразява и върху някои права на гражданите в обществото. Този конфликт трябва да бъде недвусмислено решен чрез етическа рефлексия и съответен нормативен акт.

\section{Библиография}

1. Cimino, J. J. Improving the electronic health record - are clinicians getting what they wished for? JAMA, 309(10), 2013, pp. 991-992.

2. Buntin, M. B., Burke, M. F., Hoaglin, M. C., \& Blumenthal, D. The Benefits of Health Information Technology: A Review of the Recent Literature Shows Predominantly Positive Results. Health Affairs, 30(3), 2011, pp. 464-471.

3. Currie, W. L., Seddon, J. J. M. A cross-national analysis of eHealth in the European Union: Some policy and research directions. Information \& Management, 51(6), 2014, pp. 783-797.

4. Lluch, M. Healthcare professionals' organizational barriers to health information technologies - A literature review. International Journal of Medical Informatics, 80(12), 2011, pp. 849-862.

5. Koskinen. J., Kimppa K., "An unclear question: who owns patient information?", article in "Technology and Intimacy: Choice or Coercion", Turku School of Economics, University of Turku, Finland, 2016.

6. Hall, M. A., Schulman, K. A. Ownership of Medical Information. The Journal of the American Medical Association, 301(12), 2009, pp. 1282-1284.

7. Bergelson, V. "It's Personal, but Is It Mine? Toward Property Rights in Personal Information”, U.C. Davis Law Review, 2003, №37, pp. 379-430.

8. Radin, M.J. "Property and Personhood", Stanford Law Review, 1982, No 34(5), pp. 957-1015.

9. Lessig, L., Privacy as Property, Journal Article, Social Research, 2002, pp. 247-269.

10. Baron, J. B., Property as Control: Case of Information, 18 MICH. TELECOMM. \& TECH. L. REV. 2012, p.367, p.384.

11. Hall, M. A., Property, Privacy, and the Pursuit of Interconnected Electronic Medical Records, 95 IOWA L. REV., 2010, p. 631, pp. 649-50.

12. Himmelstein, D. U., Wright, A., Woolhandler, S., Hospital computing and the costs and quality of care: A national study. American Journal of Medicine, 123, 2010, pp. 40-46.

13. Kanta. My Kanta Pages. http://www.kanta.fi/. Kellermann, A.L., Jones, S. S. What it will take to Achieve the As-Yet-Unfulfilled Promises of Health Information Technology. Health Affairs, 32(1), 2015, pp. 63-68.

14. Sittig, D. F., Singh, H. Legal, Ethical, and Financial Dilemmas in Electronic Health Record Adoption and Use. Pediatrics, 127(4), 2011, pp.1042-1047.

15. Лок Д. „Два трактата за управлението“, „ГАЛ-ИКО“, С., 1996, с. 214

16. Pateman, C., Self-Ownership and Property in the Person: Democratization and a Tale of Two Concepts. Journal of Political Philosophy, 10(1), 2002, pp. 20-53.

17. Rodwin, M. A. Patient Data: Property, Privacy \& the Public Interest. American Journal of Law \& Medicine, 36(4), 2010, pp. 586-618.

18. Koskinen, J., Kainu,V., Kimppa, K. "The concept of Datenherrschaft of patient information from a Lockean perspective", Journal of Information, Communication and Ethics in Society, Vol. 14 Issue: 1, pp.70-86, https://doi.org/10.1108/JICES-06-2014-0029; 2016.

19. Evans, B. J., Much Ado about Data Ownership. Harvard Journal of Law and Technology, 25(1), 2011, pp. 69-130.

20. Evans, B. J. Would Patient Ownership of Health Data Improve Confidentiality? Virtual Mentor, 14(9), 2012, pp. 724-732.

21. Perlin, J. B., Kupersmith, J., Information Technology and the Inferential Gap, 26 Health Aff. w192, w194, 2007.

22. Narayanan, A., Shmatikov V., Myths and Fallacies of "Personally Identifiable Information", 53 Commc'n of the ACM, 2010, p. 24, pp. 24-26.

23. Ohm, P., Broken Promises of Privacy: Responding to the Surprising Failure of Anonymization, 57 UCLA L. Rev. 1701, 2010, 1716- 31.

24. Leape L., Berwick D, Clancy C, Conway J, Gluck P, Guest, J, Lawrence D, Morath J, O'Leary D, O’Neill P, Pinakiewicz D, Isaac T. Transforming healthcare: a safety imperative. Quality and Safety in Health Care, 18, 2009, pp. 424- 428

25. Allen, A. L., Coercing Privacy, 40 Wm. \& Mary L. Rev. 723, 1999; Cohen, J. E., Examined Lives: Informational Privacy and the Subject as Object, 52 Stan. L. Rev. 1373. 2000.

26. Reichman J.H., Samuelson, P., Intellectual Property Rights in Data?, 50 Vand. L. Rev. 49, 1997, pp. 72-110.

27. Branhizer, D.D., Symposium: Cyberpersons, Propertization, and Contract in the Information Culture: Propitiation Metaphors for Bargaining Power and Control of the Self in the Information Age, 54 Clev. St. L. Rev. 69, 104. 2006.

28. Directive 96/9/EC of the European Parliament and of the Council of Europe on the legal protection of databases, 11 March 1996. https://eurlex.europa.eu/legal-content/EN/TXT/?uri=celex\%3A31996L0009.

29. Council Regulation 2016/679, 2016 O.J. (119) (EU), http://eur-lex. europa.eu/legalcontent/ EN/TXT/?uri=uriserv:OJ.L_.2016.119.01.0001.01. ENG\& toc=OJ:L:2016:119:TOC https://perma.cc/W6KN-CRFV

\section{Автор}

Мартин Мирчев (mart_mirchev@abv.bg), Албена Керековска - Катедра “Социална медицина и организация на здравеопазването", Факултет по обществено здравеопазване, Медицински университет - Варна 